Oral Abstracts

28 , cysteine $29 \mathrm{mg} / \mathrm{kg} / \mathrm{d}$ ), which is based upon the content of human milk. Commercially available formulas provide a methionine intake of $45-80 \mathrm{mg} /$ $\mathrm{kg} / \mathrm{d}$.

Aim: To quantify the requirement of methionine in presence of cysteine $(91 \mathrm{mg} / \mathrm{kg} / \mathrm{d})$ in term neonates using the Indicator Amino Acid Oxidation method.

Methods: Fully enteral fed term infants received randomly graded intakes of methionine $(3-59 \mathrm{mg} /$ $\mathrm{kg} / \mathrm{d}$ ). Breath samples were collected for ${ }^{13} \mathrm{CO} 2$ during $\mathrm{L}-\left[1-{ }^{13} \mathrm{C}\right]$ phenylalanine (indicator amino acid) infusion, measured by isotope ratio mass spectrometry and analysed by applying a biphase regression crossover analysis.

Results: Twenty-five neonates (birth weight 3.23 $\pm 0.31 \mathrm{~kg}$, gestational age $38.9 \pm 1.1 \mathrm{wks}$ ) were studied at a mean postnatal age of $13 \pm 7 \mathrm{~d}$.

With increasing methionine intake, $L-\left[1-{ }^{13} \mathrm{C}\right]$ phenylalanine oxidation decreased $(r=-0.83, p<$ $0.01)$. The mean requirement is determined at 38 $\mathrm{mg} / \mathrm{kg} / \mathrm{d}$ and the upper $95 \%$ confidence interval at $50 \mathrm{mg} / \mathrm{kg} / \mathrm{d}$ (figure).

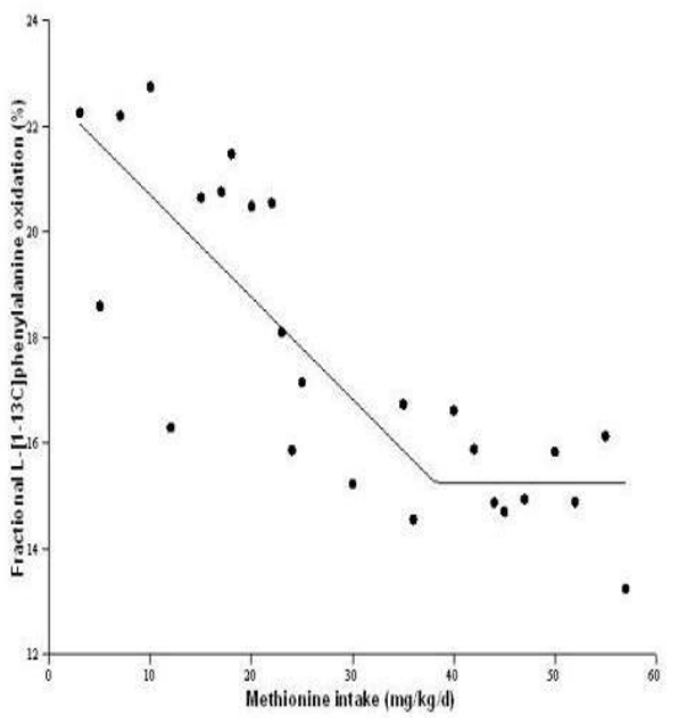

[figure ]

Conclusion: Present recommendation for methionine requirement is too low, although most, but not all, formulas provide a population safe intake when $150 \mathrm{~mL} / \mathrm{kg} / \mathrm{d}$ is consumed.

\section{ABERRANT INFLAMMATORY SIGNALLING IN AUTISM}

A.M.H. Young ${ }^{1}$, E.C. Campbell' ${ }^{2}$, S. Lynch², G.H. Doherty², M.H. Dunn ${ }^{3}$, S.J. Powis ${ }^{2}$

${ }^{1}$ School of Clinical Medicine, University of Cambridge, Cambridge, ${ }^{2}$ Bute Medical School, ${ }^{3}$ Department of Physics and Astronomy, University of St Andrews, St Andrews, UK

Introduction: Autism Spectrum Disorder (ASD) is characterized by self-absorption, a reduced ability to respond or communicate, and behavioural dysfunction. The condition has been recognised as having a strong inflammatory component. Post mortem brain samples have demonstrated the presence of neuroglia activation combined with inflammatory profiles within the cerebrospinal fluid (CSF), although little is known about the underlying molecular mechanisms initiating this process.

Methods: Age, sex and cause of death matched orbitofrontal cortex sections were donated by the Institute of Psychiatry, King's College London. Tissue micro-array was prepared by John's Hopkins University, Baltimore and obtained from the Autism Tissue Programme and the Harvard University Brain Bank.

Results: Tissues were analysed by immunoblotting for NF-kB p65 expression. A significant 2-2.5 fold increase in NF-KB expression was recorded in ASD tissue samples compared to matched tissues $(p=0.007, n=4,3)$. Furthermore, this was found to be predominately within the cell nucleus, suggestive that it was in its active form. Cell specific staining of neurons, astroglia and microglia demonstrated an increased nuclear expression of NF-kB in cells from autistic tissue where $89+3.0 \%$ of microglia expressed the active form of the molecule compared to $34+1.25 \%$ in matched controls $(p=0.002, n=4,3)$. This interestingly corresponded with a fourfold increase in the number of microglia within the tissue itself.

Conclusions: This is the first time a pro-inflammatory signalling protein has been specifically identified to be up-regulated in ASD, indicating that it may be a potential therapeutic target for treatment of the inflammatory component of the disorder. 